\title{
"Pensando o Habitar" Trajetórias de usuários de Serviços Residenciais Terapêuticos
}

\author{
"Thinking about living" Trajectories of \\ Therapeutic Residential Services users
}

Elisabete Ferreira Mângia ${ }^{1}$, Ellen Cristina Ricci ${ }^{2}$

\begin{abstract}
MÂNGIA, E. F., RICCI, E. C. "Pensando o Habitar” Trajetórias de usuários de Serviços Residenciais Terapêuticos. Rev. Ter. Ocup. Univ. São Paulo, v. 22, n. 2, p. 182-190, maio/ago. 2011.

RESUMO: Este artigo se baseia nos resultados e discussões produzidas pelo projeto "Pensando o habitar: trajetórias de usuários de serviços residenciais terapêuticos do município de Santo André (SP) que buscou conhecer a trajetória de desinstitucionalização de usuários de serviços residenciais, identificando suas principais mudanças e necessidades a partir do ponto de vista dos usuários, técnicos e cuidadores. Mais especificamente, pretendeu conhecer a experiência vivenciada pelos usuários, do hospital psiquiátrico para o serviço residencial e seus cotidianos nesses serviços. Identificar as mudanças relacionadas ao ganho de autonomia e de redes sócio-relacionais, além de conhecer as necessidades dos usuários no momento de realização do estudo. Foram realizadas: análise documental, observação participante com elaboração de diário de campo e 10 entrevistas com: usuários, cuidadores, profissionais de nível superior responsáveis pelos serviços. As entrevistas foram gravadas e transcritas na integra e submetidas á análise de conteúdo. O projeto foi aprovado pelo Comitê de Ética em Pesquisa do HC-FMUSP e obteve financiamento da Fapesp (processo 05/59564-4). Foi desenvolvido no período de outubro de 2006 à julho de 2007.
\end{abstract}

DESCRITORES: Desinstitucionalização; Moradias assistidas; Saúde mental; Terapia ocupacional/ tendências.

\footnotetext{
1. Docente do Curso de Terapia Ocupacional da FMUSP

2. Terapeuta Ocupacional. Apoio à Gestão do Distrito de Saúde Sul, Prefeitura Municipal de Campinas - SP.

Endereço para correspondência: ellenricci@gmail.com
} 
MÂNGIA, E. F., RICCI, E. C. “Pensando o Habitar”. Rev. Ter. Ocup. Univ. São Paulo, v. 22, n. 2, p. 182-190, maio/ago. 2011.

\section{INTRODUÇÃO E CONTEXTUALIZAÇÃO DO CAMPO DA PESQUISA}

$\mathrm{O}$ $s$ projetos de reforma psiquiátrica emergiram no contexto da crítica às instituições asilares, especialmente no pós $2^{\mathrm{a}}$ guerra mundial. Esta crítica deveu-se a sua baixa eficácia terapêutica, aos altos custos de manutenção, a violência com que tratavam os pacientes e a exclusão social que geravam (BARROS, 1994). Esse processo resultou em iniciativas que visavam a humanização dos hospitais psiquiátricos, a melhoria das condições de tratamento, o desenvolvimento de novas estratégias de cuidado e principalmente, a criação de serviços de saúde mental na comunidade (MÂNGIA; NICÁCIO, 2001).

No Brasil, processo similar ocorreu na década de 1980 e pode ser compreendido como uma construção contínua que engloba e articula os campos técnico-assistencial, políticojurídico, teórico-conceitual e sócio cultural (AMARANTE, 1997). Tal percurso resultou na atual Política Nacional de Saúde Mental que, dentre outras proposições, prioriza o desenvolvimento de redes de serviços de saúde mental substitutivas ao modelo asilar (BRASIL, 2006).

Atualmente, fazem parte dessa rede, dentre outros serviços: os Centros de Atenção Psicossocial (CAPS), os Centros de Convivência e Cooperativa (CECCOS) e os Serviços Residenciais Terapêuticos (SRT), que serão alvo deste artigo (MÂNGIA; NICÁCIO, 2001).

No Estado de São Paulo, a primeira experiência que visou alojar de forma diferenciada pacientes que viveram longos períodos de internação psiquiátrica, ocorreu no complexo asilar do Juqueri, situado no município de Franco da Rocha, no ano de 1984. Os então denominados "Lares Abrigados" tiveram o objetivo de albergar, em melhores condições, parcelas da população residente na instituição. Visavam favorecer a personalização dos ambientes de moradia e fomentar a autonomia dos usuários, por meio de modificações na própria estrutura hospitalar, tendo como perspectiva final a inserção de residências na comunidade (MÂNGIA; ROSA, 2002; ROSA, 2005).

A primeira experiência de criação de serviço residencial na comunidade ocorreu em 1990, na cidade de Campinas, em projeto desenvolvido pelo Hospital Cândido Ferreira. Inicialmente foi criada uma unidade hospitalar destinada às pessoas que residiam na instituição; em seguida foi implantada a primeira moradia denominada "Lar Abrigado", com seis moradores considerados mais autônomos, cujo acompanhamento era feito semanalmente por meio de reuniões entre moradores e técnicos (ROSA, 2005).
No período de realização deste estudo, os municípios brasileiros vivam o processo de passar a orientar-se pelas diretrizes da Política de Saúde Mental e implementavam a redução dos leitos psiquiátricos e a adoção dos princípios da assistência comunitária, com a criação de redes de serviços de saúde mental na comunidade. (BRASIL, 2006).

A regulamentação dos Serviços Residenciais Terapêuticos (SRT) pelo Sistema Único de Saúde (SUS) ocorreu no ano 2000 e propiciou a implementação de casas na comunidade para pessoas há longo tempo internadas. Acoplado a essa iniciativa foi criado o Programa de Volta para Casa (DVPC), que passou a oferecer a possibilidade de acesso a um auxílio, em dinheiro, para pessoas que viveram internações psiquiátricas por períodos maiores que dois anos. (BRASIL, 2000; 2006; MÂNGIA; NICÁCIO, 2003).

Tais iniciativas possibilitaram apoio importante para os processos de desinstitucionalização de pessoas moradoras em hospitais psiquiátricos. Em meados dos anos 2000, estimava-se que a população moradora em hospitais psiquiátricos vinculados ao SUS era de cerca de 15.000 pessoas, sendo 8.800 só no Estado de São Paulo (BRASIL, 2003).

Além de priorizar os egressos de longas internações, a regulamentação dos SRTs considera que podem também ser beneficiados os egressos de internação em Hospitais de Custódia e Tratamento Psiquiátrico, pessoas em acompanhamento nos CAPS, quando o problema da moradia for avaliado como fundamental ao desenvolvimento de projetos terapêuticos condizentes com as suas necessidades; e finalmente, indivíduos, em situação de rua, com transtornos mentais severos, quando inseridos em projetos terapêuticos especiais, acompanhados nos CAPs (BRASIL, 2002; 2006).

Dentre os municípios brasileiros que desenvolveram políticas de saúde mental, destacamos a experiência da cidade de Santo André, que implementou uma rede de serviços comunitários de atenção psicossocial, a partir do fechamento de um hospital psiquiátrico após graves denúncias, a Clínica de Repouso Borda do Campo (SANTO ANDRÉ, 2005).

Faziam parte dessa rede: 2 Núcleos de Atenção Psicossocial (NAPs) para adultos e 1 NAPs para usuários de álcool e drogas (NAPs AD), todos com funcionamento 24 horas. Um Núcleo de Atenção Psicossocial Infantil (NAPsi); equipes de saúde mental nos Centros de Especialidades; serviço de emergência psiquiátrica, um núcleo de projetos especiais e três serviços residenciais terapêuticos (SANTO ANDRÉ, 2005).

\section{O estudo e seus procedimentos metodológicos}


MÂNGIA, E. F., RICCI, E. C. “Pensando o Habitar”. Rev. Ter. Ocup. Univ. São Paulo, v. 22, n. 2, p. 182-190, maio/ago. 2011.

Neste artigo, serão apresentados resultados parciais do projeto de iniciação cientifica "Pensando o habitar: trajetórias de usuários de serviços residenciais terapêuticos do município de Santo André", que buscou conhecer o percurso de desinstitucionalização de usuários de serviços residenciais terapêuticos, identificando suas principais mudanças e necessidades a partir do ponto de vista dos usuários, técnicos e cuidadores. Mais especificamente pretendeu conhecer a experiência vivenciada pelos usuários do hospital psiquiátrico para o serviço residencial e seus cotidianos nesses serviços. Identificar as mudanças relacionadas ao ganho de autonomia e redes sóciorelacionais, além de conhecer as necessidades dos usuários no momento de realização do estudo.

A pesquisa se insere no campo de investigação qualitativa de base etnográfica, pois sua temática demandou o estudo interpretativo dos aspectos históricos, culturais e do cotidiano dos usuários inseridos nos serviços residenciais.

A coleta de dados foi apoiada em observação participante, desenvolvimento de entrevistas, construção de diário de campo e consulta documental. Buscou-se reconstruir as trajetórias por meio da "história de vida oral, que focaliza acontecimentos especificos tal como foram vivenciados por uma pessoa ou grupo social" (MINAYO, 2004).

Foram realizadas 10 entrevistas, gravadas e transcritas, após consentimento, sendo: quatro com usuários, quatro com cuidadores dos usuários entrevistados e dois com profissionais. A seleção dos usuários seguiu aos seguintes critérios: capacidade em responder as questões dos roteiros e tempo de internação em hospitais psiquiátricos e de permanência no serviço estudado acima de dois anos. Foram entrevistados dois usuários da residência mista e um de cada uma das demais, feminina e masculina.

Para a construção do diário de campo foi adotado um roteiro pré-estabelecido e orientado pelos objetivos do projeto, para descrever situações relevantes do cotidiano dos serviços e de seus moradores. Durante o período de 6 meses, foram realizadas 24 visitas às residências, com uma hora e meia de duração cada. O diário, de acordo com a metodologia adotada, têm valor documental e foi analisado da mesma forma que o material advindo das entrevistas.

O projeto foi aprovado pelo Comitê de Ética em Pesquisa do HC-FMUSP e obteve financiamento da Fapesp (processo 05/59564-4). Foi desenvolvido no período de outubro de 2006 à julho de 2007.

\section{Apontamentos teóricos}

Para nos situarmos em relação ao debate sobre serviços residenciais terapêuticos e as perspectivas que oferecem para a atenção e construção de projetos terapêuticos, apresentamos um breve percurso reflexivo baseado nas proposições de autores, do campo da reforma psiquiátrica, sobre os conceitos de desinstitucionalização, reabilitação psicossocial, poder contratual e autonomia. A partir dessa reflexão foi construída a base para a compreensão dos dados e do contexto desta pesquisa, lembrando ainda que tal percurso ocorreu sempre em consonância aos objetivos inicialmente propostos.

Sobre o conceito de desinstitucionalização, Rotelli (2001) descreve que em diversos países que desenvolveram políticas de saúde mental, tais como Estados Unidos, Inglaterra e França, o processo de desinstitucionalização se restringiu a desospitalização, a partir de altas hospitalares e redução gradual de leitos em hospitais psiquiátricos. Por outro lado, a experiência de desinstitucionalização desenvolvida na Itália, a partir dos anos 1970, buscou a superação do modelo asilar, propondo a desconstrução dos manicômios e de suas práticas e a construção de novos serviços, saberes e intervenções em saúde mental, colocando o foco não mais na doença e sim no sujeito, buscando a emancipação das pessoas com transtorno mental. Nesse contexto se percebe a mudança e ampliação do conceito de desinstitucionalização que passou a contemplar as múltiplas dimensões da vida humana (ROTELLI, 2001).

Saraceno (2001), ao discutir as novas práticas de desinstitucionalização, propõem que a reabilitação psicossocial deva ser um processo de reconstrução e de exercício pleno da cidadania, desenvolvido a partir de três eixos principais: A) o morar, que estaria ligado às condições tanto materiais quanto de acolhida e de apropriação da moradia e do ambiente doméstico; B) as trocas de identidades, relacionadas a construção de vínculos e ampliação das redes sociais de cada sujeito, o que envolve o trabalho com a comunidade, família e demais sujeitos e/ou grupos, que possam oferecer apoio nas situações do cotidiano; e C) a produção e troca de mercadorias e valores; que envolve o trabalho com geração de renda e participação efetiva no mercado de trabalho ou de trocas materiais e simbólicas. Contemplando esses 3 aspectos centrais, a intervenção em reabilitação psicossocial teria o intuito de restituir ao sujeito com transtorno mental seu poder contratual.

O conceito de poder contratual se coloca como central e pode ser compreendido como a capacidade do sujeito de realizar trocas com o contexto social a partir das relações que estabelece com outros sujeitos, grupos e/ou instituições, bem como a ampliação de sua possibilidade de negociação e de elaboração de projetos que possam contribuir para 
modificar as condições concretas de sua vida. Acredita-se que com o aumento da sua contratualidade social o sujeito amplia sua autonomia (KINOSHITA, 2001).

Nessa linha reflexiva, a autonomia é entendida como a capacidade de um indivíduo gerar normas para a própria vida, de acordo com as diversas situações vivenciadas no cotidiano. Essa autonomia pode ser identificada pelas atividades cotidianas que realiza, como sua possibilidade e liberdade de circular nos espaços sociais para gerir seu cotidiano: fazer compras, passear, frequentar a escola, etc. Envolve também a gestão da vida pessoal e doméstica: a tomada de decisão sobre os horários para comer, dormir, trabalhar, preparar as próprias refeições, comprar alimentos, por exemplo, sem a necessidade de ajuda técnica ou de outros cuidadores (KINOSHITA, 2001).

Saraceno (2001) chama a atenção para a necessidade de diferenciarmos o morar em dois aspectos: o estar e o habitar. Assim, o estar significaria ocupar um espaço sem que haja apropriação do mesmo, quer seja material, simbólica ou emocional. Já o habitar significaria a possibilidade de ocupar o espaço onde se vive com crescente grau de apropriação simbólica, material e emocional. O sujeito que habita um determinado espaço se apropria materialmente e emocionalmente deste e dos objetos que o compõem, bem como interage afetivamente com os demais que ali vivem.

Ao assumir o trabalho sobre o habitar, o processo de reabilitação psicossocial deve se voltar para o espaço real da casa e identificar a forma como o sujeito nela habita para promover a conquista da casa (concreta) e a ativação dos desejos e habilidades para o habitar (SARACENO, 2001).

Neste trabalho, para descrever o cotidiano das casas e dos respectivos moradores, se levou em consideração a possibilidade do habitar em relação a apropriação da casa e da participação em suas dinâmicas básicas, como limpeza, preparo das refeições, relações com os demais moradores, etc, pois se compreendeu que a possibilidade do habitar será maior se houver horizontalização das relações entre usuários e serviços, em presença permanente de diálogo e interação grupal, como fator facilitador da conquista, pelo usuário, de sua autonomia.

A adoção dessa perspectiva teórica na análise dos dados e, posteriormente, nas considerações finais, contribuiu para a compreensão sobre a importância dos Serviços Residenciais Terapêuticos no processo de desinstitucionalização e reabilitação das pessoas com transtorno mental, com longo tempo de internação, bem como para descrever e analisar as relações estabelecidas entre usuários no contexto da vida diária.

\section{Caracterização dos Serviços Residenciais Terapêuticos}

No período de realização do estudo, os 3 SRTs do município de Santo André eram administrados pela Organização Social De Volta para Casa (OS), que recebia parte dos recursos financeiros destinados a saúde mental do município, por meio de convênio firmado com a Prefeitura Municipal. Estes serviços residenciais atendiam 25 pessoas, 12 homens e 13 mulheres, com idades que, na época, variavam entre 38 e 87 anos. A maioria eram egressas de longas internações em hospitais psiquiátricos: nove procedentes da Clínica de Repouso Ribeirão Pires, seis da Clínica de Repouso Borda do Campo; um do Hospital Psiquiátrico Vera Cruz; um do Hospital Psiquiátrico Pinel; um do Hospital Psiquiátrico de Paracambi, no Rio de Janeiro; e sete eram usuárias da própria rede de saúde mental do município de Santo André. Os serviços eram acompanhados por dois cuidadores por período diurno e noturno, em regime de plantões de 12 horas, 24 horas diárias, sete dias por semana.

As residências estavam localizadas no bairro Bangú, próximas a um NAPs, que se constituía como o serviço de saúde mental de referência para a região e para as residências e seus respectivos usuários.

Duas delas eram compostas apenas por usuários de mesmo sexo e uma era mista. Assim existiam, de acordo com a nomenclatura atribuída pelos técnicos: a moradia masculina, a feminina e a mista, esta última composta por moradores mais dependentes de cuidados.

Estavam instaladas em casas grandes, que possibilitavam a acomodação de até oito pessoas com conforto, de forma que em cada quarto dormiam de dois a três moradores.

Eram coordenadas por uma psicóloga e acompanhadas por uma terapeuta ocupacional, que realizavam reuniões semanais com os moradores em cada residência e visitas cotidianas. Além disso, se revezavam na administração das compras de alimentos, roupas e outras necessidades dos moradores.

Cada usuário era acompanhado com maior proximidade por dois profissionais do NAPS e um cuidador da residência. Os cuidadores eram pessoas selecionadas na própria comunidade, contratados pela OS após um processo de seleção. Na época esse grupo era composto por 25 pessoas, 6 homens e 19 mulheres, que se revezavam em turnos diurnos e noturnos de trabalho, com duração de 12 horas cada.

$\mathrm{Na}$ residência feminina residiam 7 mulheres, sendo 6 egressas de hospitais psiquiátricos e uma usuária que 
MÂNGIA, E. F., RICCI, E. C. “Pensando o Habitar”. Rev. Ter. Ocup. Univ. São Paulo, v. 22, n. 2, p. 182-190, maio/ago. 2011.

chegou à residência por intermédio do NAPs II, visto que se encontrava sem residência após adoecimento do único familiar que dela cuidava. Três delas recebiam auxílio do programa De Volta para Casa (DVPC) e uma desenvolvia atividades na Organização Social De Volta para Casa, a partir de vínculo informal, mas remunerado. Quatro não recebiam nenhum tipo de benefício: dois por não disporem de documentos e as demais por não atenderem aos critérios para acessarem os benefícios.

$\mathrm{Na}$ residência masculina moravam oito homens, sendo seis egressos de hospitais psiquiátricos e dois encaminhados respectivamente pelo NAPs I e pelo Hospital Geral Municipal, ambos por abandono familiar e falta de moradia. Quatro recebiam aposentadoria por invalidez e desses, três também recebiam auxílio DVPC. Os demais não recebiam nenhum benefício: três deles por falta de documentos e um por não preencher os critérios para acesso aos benefícios possíveis.

$\mathrm{Na}$ residência mista moravam cinco homens e cinco mulheres. Seis deles eram egressos de hospitais psiquiátricos e quatro foram encaminhados pelo NAPs I e NAPs II, todos por abandono familiar e social e falta de moradia. Seis recebiam aposentadoria por invalidez; desses, quatro também recebiam auxílio DVPC. Um deles recebia apenas DVPC. Três usuários não recebiam nenhum tipo de benefício: dois por não possuírem documentos e um por não atender aos critérios para acesso aos benefícios.

Em cada casa existia um banheiro reservado para os técnicos, cuidadores e visitantes. Na residência feminina e na mista, embora eles permanecessem abertos, os cuidadores orientavam os usuários a não utilizá-los. $\mathrm{Na}$ residência masculina esse banheiro permanecia trancado. Todas dispunham de telefones, mas os usuários só podiam utilizá-los mediante autorização dos cuidadores.

Nas casas havia sempre um local reservado à guarda de prontuários, medicamentos e cadernos de plantão, que eram administrados pelos cuidadores, para controle da medicação e descrição de acontecimentos diários. Ficavam acessíveis a qualquer pessoa. Nesses documentos havia informações sobre o controle medicamentoso e intercorrências ligadas a mudanças de comportamento dos moradores.

Tais aspectos, além de outros que serão descritos ou comentados a seguir, conferiam um caráter institucional às residências, o que transparecia como uma descaracterização do projeto residencial preconizado pelo Ministério da Saúde.

\section{Cotidiano dos usuários dos Serviços Residenciais}

Como componente central de seu cotidiano os moradores frequentavam o NAPS. Na residência feminina essa frequência se dava quatro vezes por semana, exceto para uma moradora que trabalhava e assim participava de apenas uma oficina semanal no NAPS e outra que não apresentava condições para locomoção

Na residência masculina a frequência ao NAPS era de três vezes por semana, exceto para um morador que apresentava quadro clínico que impossibilitam a sua locomoção. Já na residência mista a freqüência ao NAPS era facultativa, e cada morador podia decidir sobre os dias de sua preferência.

Essa rotina era estabelecida pela equipe técnica de cada serviço em acordo com os técnicos de referência de cada usuário no NAPs II, embora ficasse a cargo dos cuidadores de plantão sua efetivação. O processo de observação possibilitou verificar que, no geral, os cuidadores respeitavam o desejo de cada usuário em ir ou não ao NAPS.

As casas recebiam as refeições, almoço e jantar, já preparadas, fornecidas pela Companhia Regional de Abastecimento Integrado de Santo André (CRAISA), empresa que atendia aos serviços de saúde do município. As refeições eram preparadas no Hospital Municipal. Eram sempre compostas por arroz, feijão, vegetal cozido e carnes variadas; embaladas em alumínio e entregues por volta das $11 \mathrm{~h}$ no almoço e $17 \mathrm{~h}$ no jantar. Os alimentos para o café da manhã eram entregues semanalmente. Outros alimentos tais como frutas, legumes, açúcar e café eram adquiridos em feiras livres ou mercados próximos das residências pelas técnicas responsáveis e financiados pela Organização Social.

O mesmo mecanismo também era utilizado para oferecer a alimentação aos usuários do NAPS; assim, os moradores que tinham indicação para estarem no NAPS no horário das refeições, deveriam receber suas refeições neste serviço, o que muitas vezes gerava desencontros. Apenas na residência mista alguns moradores realizavam compras e preparavam as refeições.

O cuidado com as roupas era realizado pelos cuidadores. Parte da roupa era lavada na lavanderia do Hospital Municipal de Santo André e parte nas máquinas de lavar disponíveis em cada residência. Muitas roupas eram conseguidas como doação, mas havia também compras realizadas pela OS.

Observou-se que apenas seis moradores possuíam autonomia para cuidar de suas roupas, três, dentre eles, também compravam suas roupas sem acompanhamento.

Cada casa contava com uma auxiliar de limpeza, contratada pela OS, que realizava a limpeza diária. Nos 
finais de semana a manutenção da limpeza dependia da colaboração dos moradores e cuidadores.

\section{Caracterização dos usuários entrevistados}

Todos os usuários entrevistados tiveram histórico de internações psiquiátricas por mais de 15 anos, com histórias semelhantes de perdas relacionais e sócio familiares, além da vivência da precarização econômica. Dos quatro usuários, três chegaram às residências após o fechamento de hospitais psiquiátricos e um após alta hospitalar. Dois possuíam documentos pessoais, o que possibilitou a aquisição de benefícios; os demais não possuíam sequer registros nas instituições onde viviam.

A partir das trajetórias compiladas se pode confirmar que as instituições asilares produzem grave processo de desfiliação das pessoas que nelas vivem por longos períodos. As rupturas com as histórias de vida se evidenciam também pela falta de documentação pessoal e informações relevantes em prontuários, que geralmente mostram apenas as abusivas prescrições farmacológicas.

\section{Fragmentos das histórias dos entrevistados}

1. André ${ }^{1}$, natural da cidade de Santo André, na época com 48 anos. Contou que, morava em uma casa precária, de tábuas e terra batida. Após a morte da mãe, sofreu uma crise durante a qual agrediu o pai, que veio a falecer. Cumpriu medida de segurança em manicômio judiciário e depois foi transferido para a Clínica de Repouso Borda do Campo. Recebia visitas esporádicas de sua irmã e de um tio que residia no sul do estado de Minas Gerais. Após a alta hospitalar continuou morando no hospital. Recebia o auxílio concedido pela Lei Orgânica da Assistência Social - LOAS. Sua irmã não o visitou mais, após mudança de residência, mas ainda recebia telefonemas do tio. Chegou ao serviço residencial após o fechamento do hospital onde residia.

2. Selma, então com 41 anos, era natural da cidade de São Paulo. Foi abandonada na infância. Sua mãe sofria de transtorno e faleceu muito jovem. O pai tinha outros filhos e optou por cuidar apenas da irmã gêmea de Selma. Viveu na Fundação de Bem Estar do Menor (FEBEM). Teve uma filha com um funcionário dessa instituição, que assumiu a guarda da criança. Após atingir a maioridade passou a morar em albergues em São Paulo. Apresentou inúmeras crises de agressividade até que foi internada no
Hospital Psiquiátrico Pinel onde morou até a transferência para o serviço residencial.

3. Fábio, natural do estado de Minas Gerais, estava com 72 anos. Casado, teve dois filhos, saiu da zona rural em busca de tratamento e perdeu o contato com a família. Relata que era muito agressivo com os familiares. Não lembrava ao certo o nome de sua cidade, passou por muitas internações e contou que seus documentos foram perdidos nesse processo. Chegou ao serviço residencial após o fechamento do hospital onde morava.

4. Meire, natural do estado do Paraná, tinha em torno de 55 anos. Morava com os pais e irmão. Foram abandonados pelo pai e a mãe faleceu. Contou que passou a morar só e teve duas filhas, mas não sabia onde estavam. Seus documentos também foram perdidos durante o período de internação.

\section{Reflexões}

O cotidiano dos moradores se assemelhava nas atividades do dia a dia e na frequência ao NAPS (pelo menos uma vez por semana). Dois deles também frequentavam a escola e uma trabalhava na OS. Três deles já haviam frequentado um programa de educação para adultos. Desenvolviam rotinas semelhantes e possuíam, com algumas diferenças, independência no cuidado pessoal e na circulação até o serviço assistencial. Já para outras ações, mantinham um grande grau de dependência dos cuidadores.

Todos tinham como aspecto semelhante a grande dificuldade na comunicação verbal e comprometimentos cognitivos, talvez também relacionados ao uso abusivo de medicação presente em suas trajetórias institucionais. Por outro lado, ao compilar suas histórias, se evidenciam importantes melhoras clínicas e psicossociais a partir do ingresso nos serviços residenciais.

O relato dos cuidadores mostra que a maior parte dos moradores chegou ao serviço como "bichos assustados", apresentando muitos episódios de grave instabilidade e extrema dificuldade de comunicação. Relatam também que o processo de adaptação ao novo cenário demandou muito trabalho e empenho da equipe envolvida, mas que os resultados foram compensadores.

Os benefícios que recebiam possibilitavam, dentre outras, a compra de pertences pessoais, alimentos, idas a

1. Serão utilizados nomes fictícios para identificar os usuários entrevistados. 
MÂNGIA, E. F., RICCI, E. C. “Pensando o Habitar”. Rev. Ter. Ocup. Univ. São Paulo, v. 22, n. 2, p. 182-190, maio/ago. 2011.

restaurantes, passeios, etc. o que tem grande significado para pessoas que viveram por tanto tempo isoladas e excluídas do convívio social.

Percebeu-se, nos relatos dos entrevistados e na vivência de campo, que os moradores ainda tinham pouco poder contratual na relação com a equipe técnica e com os cuidadores. As relações entre eles e a equipe mantinhamse verticalizadas e muitas restrições desnecessárias ou, no mínimo, discutíveis, eram impostas aos moradores.

Quando perguntados se consideravam que o serviço residencial era a sua casa foram unânimes ao responderem que não. Percebiam a moradia como um hospital diferente e melhor e como um lugar de passagem no qual podiam alimentar o desejo de ter ou voltar para a própria casa.

Apesar disso, foi possível atestar que de diferentes formas, essas pessoas iam conquistando e se apropriando simbólica e emocionalmente de novos espaços de vida a partir da possibilidade de habitar uma casa. As interações entre o grupo de moradores, embora limitadas, também ocorriam em muitos momentos e a partir de diversos desafios cotidianos vinculados à manutenção das rotinas diárias e às diversas necessidades colocadas para um viver junto. Momentos de conflito, mas também de solidariedade e trocas compunham o novo cotidiano desse grupo, como ocorre na vida da maior parte das pessoas.

A partir do novo contexto configurado pelos serviços residenciais, os sujeitos puderam encontrar múltiplas possibilidades de trocas efetivas, circulação e inclusão social, mas esses aspectos necessitam ser estimulados e muitas vezes assegurados pelos profissionais que atuam nos SRTs e nos NAPS.

Deve-se reconhecer que as posturas técnicas e políticas dos profissionais envolvidos no processo de reabilitação podem proporcionar a construção de espaços de trocas, inclusão e ganho de autonomia dos moradores.

Para Saraceno (2001), a reabilitação psicossocial deve ser um processo de reconstrução e de exercício pleno da cidadania, capaz de garantir condições para a qualificação da moradia em seus múltiplos aspectos. Percebeu-se que os SRTs estudados, embora propiciassem aos moradores a base material, relacional e assistencial básica e indispensável, apresentavam entraves na superação da cultura de invalidação desses sujeitos, não permitiam a apropriação plena das casas como lócus para habitar um território existencial mais amplo e completo, capaz de ativar e realizar habilidades e desejos das pessoas.

Evidentemente foram produzidas mudanças importantes na vida dos sujeitos, estando a principal delas referida aos seus reconhecimentos como sujeitos de direito, à apropriação da possibilidade de circular, de ir e vir e de percorrer, conhecer e interagir novamente com o território onde se vive. Possibilidades que todos haviam perdido com o processo de institucionalização. (Mângia, Marques, 2004).

\section{Novas necessidades}

As entrevistas mostraram também a emergência de necessidades ligadas a ampliação da autonomia, maior apropriação dos espaços da casa e da comunidade, aumento do poder contratual em relação ao serviço e cuidadores e maior investimento na re-construção de redes sócio-relacionais e familiares que pudessem criar nova interdependência e assim reduzir a grande dependência desses sujeitos em relação às equipes das casas e do NAPS.

Três dos entrevistados não cozinhavam, nem cuidavam de todas as suas roupas, além de não participarem das tarefas de organização da casa. Apenas Selma demostrava mais autonomia e elaboração sobre o processo vivido até sua chegada ao SRT.

Três dos entrevistados manifestaram desejo de fazer coisas diferentes, a exemplo de ler e escrever. A falta de documentos também foi referida como um impedimento para a autonomia

Apesar de referirem com clareza algumas necessidades, todos eles tinham dificuldades para concretizar seus desejos e se organizarem melhor no cotidiano. Viu-se que muitas dessas dificuldades estavam relacionadas à própria forma como os profissionais faziam a gestão da moradia, muitas vezes impondo regras sem um processo de construção e negociação junto com os moradores. Exemplo disso eram as proibições do uso de telefone, os horários rígidos de refeição e a obrigatoriedade da frequência cotidiana no NAPS.

Também foi recorrente o desejo de ter a casa própria, voltar para a antiga casa e/ou reencontrar sua família de origem, o que trouxe a necessidade de reflexão sobre o papel que os serviços residenciais estavam desempenhando para essas pessoas e especialmente sua defasagem em ocupar o lugar da casa no imaginário e suas vivências cotidianas. .

Neste contexto seria importante que o serviço de saúde mental e a equipe envolvida na gestão de um SRT pudessem rever seus papéis e voltar-se para a construção de projetos terapêuticos mais participativos e dinâmicos e que buscassem responder, de fato, às novas necessidades surgidas a partir do processo de desinstitucionalização e reapropriação dos percursos de vida na nova casa.

Nesse sentido, se evidencia a necessidade de serviços que construam projetos de reabilitação psicossocial de 
acordo não mais com a lógica asilar, mas sim na lógica da cidadania, com apropriação da consciência, acesso e usufruto de direitos (MÂNGIA; MARQUES, 2004).

\section{CONSIDERAÇÕES FINAIS}

O projeto permitiu conhecer os serviços residenciais e seus moradores e refletir sobre a importância desses serviços para os processos de desinstitucionalização. As visitas e entrevistas realizadas propiciaram a aproximação com as rotinas e o cotidiano dos moradores a partir da qual foi possível discutir os pontos de força e fragilidades da experiência em curso no município de Santo André.

Embora cumprissem um papel importante no processo de desinstitucionalização e inclusão social dos sujeitos, pareceram não explorar adequadamente a missão preconizada pela orientação do Ministério da Saúde. Ficou evidente a tendência à institucionalização das relações entre profissionais e usuários e a reprodução de padrões tradicionalmente encontrados em instituições asilares, como as rotinas empobrecidas e ritualizadas.

A identificação da residência como um hospital de melhor qualidade, verbalizada pelos entrevistados, se confirmou nas rotinas e na forma de gerenciamento de cada residência, que contribuía para reforçar o viés institucionalizante da experiência.

A carência de formação técnica, mais atualizada e crítica, pareceu ser um dos principais fatores que contribuía para a dificuldade de aprimoramento da experiência, uma vez que a equipe não dispunha de um repertório adequado para a condução das mudanças pretendidas nesse novo cenário e se limitava, muitas vezes, a reproduzir uma postura rígida e disciplinar. Esse aspecto transparecia tanto na relação com os usuários como com os cuidadores, que na medida em que não recebiam orientações claras se limitavam a utilizar os recursos pessoais que possuíam.

Finalmente considerou-se que, ao lado do aprimoramento da formação técnica, se faz necessário a produção de manuais e orientações mais claras e objetivas, que possam ser reproduzidas e propiciar a implantação e reformulação de serviços residenciais no sentido da qualificação progressiva dessas experiências e a ruptura com as tendências asilares ainda tão arraigadas nas culturas técnicas e sociais.

MÂNGIA, E. F.; RICCI, E. C. "Thinking about living” Trajectories of Therapeutic Residential Services users. Rev. Ter. Ocup. Univ. São Paulo, v. 22, n. 2, p. 182-190, maio/ago. 2011.

\begin{abstract}
This article is based on the results and discussions generated by the project "Thinking of living: trajectories of users of therapeutic residential services of the city of Santo André (SP)", that aimed to know the deinstitutionalization trajectories of users of residential services, identifying their major changes and needs from the viewpoint of users, technicians and caregivers. More specifically, we wanted to know the experience of users, since they left the psychiatric hospital so far in the residential service and their daily lives in these services. It aimed to identify the changes related to the gain of autonomy and social-relational networks, besides knowing the needs of users at the moment of the study. We developed: documental analysis, participant observation with field diary elaboration and 10 interviews with users, caregivers and superior level professionals responsible for the services. The interviews were typed and fully transcribed and submitted to content analysis. The project was approved by the Ethic Committee in Research of HC-FMUSP and obtained funding of FAPESP (process number: 05/59564-4). I was developed during the period of 2006 October and 2007 July.
\end{abstract}

KEY WORDS: Deinstitutionalization; Assisted living facilities; Mental health; Occupational therapy/trends.

\title{
REFERÊNCIAS
}

AMARANTE, P. (Coord.). Loucos pela vida: a trajetória da reforma psiquiátrica no Brasil. Rio de Janeiro: Fiocruz, 2003.

BARROS, D. D. Jardins de Abel: desconstrução do manicômio de Trieste. São Paulo: Edusp, 1994.

BRASIL, Ministério da Saúde. Portaria 106 de 11 de fevereiro de 2000. Brasília, DF. DOU. 14 fev. 2000. 
MÂNGIA, E. F., RICCI, E. C. “Pensando o Habitar”. Rev. Ter. Ocup. Univ. São Paulo, v. 22, n. 2, p. 182-190, maio/ago. 2011.

BRASIL. Ministério da Saúde. Relatório de gestão - 2003-2006. Saúde mental no SUS: acesso ao tratamento e mudança do modelo da atenção. Brasília, 2006.

BRASIL. Ministério da Saúde. Secretaria Executiva. Legislação em saúde mental, 1990-2002. 3a. ed. Brasília, 2002.

KINOSHITA, R. T. Contratualidade e reabilitação psicossocial. In: PITTA, A. (Org.). Reabilitação psicossocial no Brasil. 2a ed. São Paulo: Hucitec, 2001.

MÂNGIA, E. F.; MARQUES, A. L. M. Desinstitucionalização e serviços residenciais terapêuticos: novas perspectivas para o campo da reabilitação psicossocial. Rev. Ter. Ocup. Univ. São Paulo, v. 15, n. 3, p. 129-135, 2004.

MÂNGIA, E. F.; NICACIO, F. Terapia ocupacional em saúde mental: tendências principais e desafios contemporâneos. In: DE CARLO, M. M. R. P.; BARTALOTTI, C. C. Terapia ocupacional no Brasil: fundamentos e perspectivas. São Paulo: Plexus, 2001. p. $63-80$.

MÂNGIA, E. F.; NICÁCIO, M. F. DE S. "De Volta Para Casa": reconhecendo o direito de viver fora dos manicômios [Editorial].
Rev. Ter. Ocup. Univ. São Paulo, v. 14, n. 3, 2003.

MÂNGIA, E. F.; ROSA, C. A. Desinstitucionalização e serviços residenciais terapêuticos. Rev. Ter. Ocup. Univ. São Paulo, v. 13, n. 2, p. 71-7, 2002.

MINAYO, M. C. S. O desafio do conhecimento. Pesquisa qualitativa em saúde. São Paulo: Hucitec-ABRASCO, 2004.

ROSA, C. A. Serviço residencial: possibilidades e limites no processo de desinstitucionalização [Dissertação]. São Paulo, 2005. Escola de Enfermagem da USP.

ROTELLI,F.; LEONARDIS, O.; MAURI,D.Desinstitucionalização, uma outra via. In ROTELLI, et al. Desinstitucionalização, São Paulo: Hucitec, 1990.

SANTO ANDRÉ. Coordenadoria de Saúde Mental de Santo André. Disponível em: <http://www.santoandre.sp.gov.br/saude/ mental>.

SARACENO, B. Libertando identidades: da reabilitação à cidadania possível. Belo Horizonte: Te Corá/Instituto Franco Basaglia, 1999. 